\title{
Influence of COVID-19 confinement measures on appendectomies in Germany-a claims data analysis of 9797 patients
}

\author{
Matthias Maneck ${ }^{1} \cdot$ Christian Günster $^{1} \cdot$ Hans-Joachim Meyer $^{2} \cdot$ Claus-Dieter Heidecke $^{3} \cdot$ Udo Rolle $^{4}$ (I)
}

Received: 15 September 2020 / Accepted: 17 November 2020 / Published online: 4 December 2020

(C) The Author(s) 2020

\begin{abstract}
Purpose COVID-19 pandemic had multiple influences on the social, industrial, and medical situation in all affected countries. Measures of obligatory medical confinement were suspensions of scheduled non-emergent surgical procedures and outpatients' clinics as well as overall access restrictions to hospitals and medical practices. The aim of this retrospective study was to assess if the obligatory confinement (lockdown) had an effect on the number of appendectomies (during and after the period of lockdown). Methods This retrospective study was based on anonymized nationwide administrative claims data of the German Local General Sickness Fund (AOK). Patients admitted for diseases of the appendix (ICD-10: K35-K38) or abdominal and pelvic pain (ICD-10: R10) who underwent an appendectomy (OPS: 5-470) were included. The study period included 6 weeks of German lockdown (16 March-26 April 2020) as well as 6 weeks before (03 February-15 March 2020) and after (27 April-07 June 2020). These periods were compared to the respective one in 2018 and 2019.

Results The overall number of appendectomies was significantly reduced during the lockdown time in 2020 compared to that in 2018 and 2019. This decrease affects only appendectomies due to acute simple (ICD-10: K35.30, K35.8) and non-acute appendicitis (ICD-10: K36-K38, R10). Numbers for appendectomies in acute complex appendicitis remained unchanged. Female patients and in the age group 1-18 years showed the strongest decrease in number of cases.

Conclusion The lockdown in Germany resulted in a decreased number of appendectomies. This affected mainly appendectomies in simple acute and non-acute appendicitis, but not complicated acute appendicitis. The study gives no evidence that the confinement measures resulted in a deterioration of medical care for appendicitis.
\end{abstract}

Keywords COVID 19 pandemic $\cdot$ Confinement $\cdot$ Lockdown $\cdot$ Appendectomy $\cdot$ Administrative claims data

\section{Introduction}

COVID-19 pandemic had multiple influences on the social, industrial, and medical situations in the affected countries. Confinement measures to minimize the number of infected persons included social distancing, avoidance of contact, and formal lockdown in respective regions.

Udo Rolle

udo.rolle@kgu.de

1 AOK Research Institute (WIdO), Berlin, Germany

2 German Society of Surgery, Berlin, Germany

3 Department of General, Visceral, Thoracic and Vascular Surgery, Universitätsmedizin Greifswald, Greifswald, Germany

4 Goethe-University Frankfurt, University Hospital, Department of Paediatric Surgery and Paediatric Urology, Frankfurt, Germany
Medical confinement measures had been introduced from 16 March 2020 in Germany, with suspension of all scheduled hospitalizations, elective operations, outpatients' clinics, stoppage of screening measures (e.g., mammography), and reduced opening hours of practices. Main aspect of all measures was to avoid contacts in the medical setting and spare protective equipment.

It had been assumed that COVID-19 pandemic would have had a major impact not only on the delivery of elective care but also on emergency procedures. A recent report from Italy has shown a reduced rate of hospital admissions for acute coronary syndrome during COVID-19 outbreak [1].

Appendectomy is one of the most frequent abdominal surgeries in all age groups. Appendectomy usually would be performed in patients with simple acute and complex acute appendicitis.

Early reports showed an increased number of complicated appendicitis during confinement period in GB [2]. This has 
also been shown in a small case series, which presented seven pediatric cases with advanced appendicitis due to delayed presentation [3].

Medical associations in Germany expressed concerns that the medical confinement measures might lead to an increase of patients with complicated appendicitis due to the delay of presentation to the hospitals [4].

The aim of this retrospective study was to assess if the medical lockdown in Germany had an effect on the number of appendectomies (during and after the period of lockdown).

\section{Material and methods}

This retrospective cohort study was based on anonymized nationwide administrative claims data of the German Local General Sickness Fund (AOK), the largest provider of statutory health care insurance in Germany. The AOK covers approximately $30 \%$ of the population. The claims data includes age and sex as well as data from inpatient episodes, including diagnoses, procedures, and length of stay. Diagnoses were coded according to the 10th revision of the International Classification of Diseases (ICD-10). Procedures were documented using the German version of the International Classification of Procedures in Medicine (ICPM), the "Operationen- und Prozedurenschlüssel" (OPS).

We included patients aged 1 year or older admitted for diseases of the appendix (ICD-10: K35-K38) or abdominal and pelvic pain (ICD-10: R10) who have undergone an appendectomy (OPS: 5-470). The study period included the 6 weeks of German lockdown (16 March-26 April 2020) as well as 6 weeks before (03 February-15 March 2020) and after (27 April-07 June 2020). These three periods correspond to the calendar weeks: 6-11 (before), 12-17 (lockdown), 1823 (easing). Similarly, patients were included for 2018 and 2019 with respect to the Easter holidays in 2020 (calendar week 15). To avoid confounding effects, the calendar weeks of 2018 and 2019 were shifted by plus 2 and minus 1 week with respect to the Easter holidays respectively.

The primary outcome was incidence of hospital admissions. We calculated incidence rates for the primary outcome by dividing the number of cumulative admissions by the number of days for each time period.

Patients were stratified by appendicitis stage, gender, and age. Appendicitis stages were classified as complex acute appendicitis (CAA), simple acute appendicitis (SAA), and nonacute appendicitis (NAA). CAA exhibit a generalized or localized peritonitis with perforation or rupture or a peritoneal abscess (ICD-10: K35.2, K35.31, K35.32). SAA was acute but without the aforementioned properties (ICD-10: K35.30, K35.8). NAA included other or non-specified types of appendicitis, other diseases of the appendix, or abdominal and pelvic pain (ICD-10: K36, K37, K38, R10). According to their age, patients were divided into three groups: 1-18 years, 19 64 years, and $\geq 65$ years.

Patient demographics, appendicitis stage, Elixhauser score, and length of stay were summarized as descriptive statistics. The Elixhauser score, as proposed by van Walraven et al., was used to assess patient comorbidities [5]. This score ranges from -19 to 89 . The closer this score is to zero, the fewer comorbidities are present. Categorical data were presented as percentage, and numeric data as mean with standard deviation, respectively. Trends among the three periods within 2020 were compared using univariate $\chi^{2}$ or Kruskal-Wallis tests using a significance level of 0.05 .

Case reductions were determined by incidence rate ratios (IRR) comparing each period of 2020 with the corresponding calendar week of 2019 using Poisson's regression to model the number of admissions per day [1]. Bonferroni's adjustment was done to correct $p$ values for comparing multiple patient groups (factor 144).

To investigate annual changes in the number of cases unrelated to the pandemic, periods of 2019 were additionally compared to 2018.

All evaluations were performed with the software STATA16.0 (StataCorp, College Station, TX).

\section{Results}

\section{Appendectomy rates in $\mathbf{2 0 2 0}$}

The study comprised 9797 AOK cases who underwent an appendectomy in 2020. Mean age was 34.5 years and $48.0 \%$ were female patients. Overall, $23.7 \%$ were diagnosed for CAA, $70.1 \%$ for SAA, and $6.2 \%$ for NAA. Detailed descriptive statistics for each period during the pandemic are shown in Table 1. With respect to all patients, the periods before, during, and after the lockdown significantly differ in mean incidence per day, age, proportion of female sex, CAA, and NAA.

With start of the lockdown, the daily case rate fell and increased again as the relaxations took effect, but not to previous levels $(85.5,69.4,78.4, p<0.001)$. This trend was also observed when considering only SAA or NAA cases. However, for CAA cases, no significant differences between the periods were observed.

These appendicitis stage-specific changes in the daily case rate result in different distributions of appendicitis stages in the three periods. Within the lockdown and easing period, the proportion of CAA cases is higher and the proportion of NAA cases is lower as compared to the before period. The difference in the easing period is not as strong as during the lockdown (CAA: $21.2 \%, 27.0 \%, 23.6 \%, p<0.001$; NAA: $8.6 \%$, $3.8 \%, 5.7 \%, p<0.001)$. 
Table 1 Patient demographics of hospital admissions with appendectomy in 2020 ( $A L L$, all appendicitis stages; $C A A$, complex acute appendicitis; $S A A$, simple acute appendicitis; $N A A$, non-acute appendicitis)

\begin{tabular}{|c|c|c|c|c|}
\hline Week number & $\begin{array}{l}\text { Before } \\
6-11\end{array}$ & $\begin{array}{l}\text { Lockdown } \\
12-17\end{array}$ & $\begin{array}{l}\text { Easing } \\
18-23\end{array}$ & $p$ \\
\hline ALL cases & 3591 & 2914 & 3292 & \\
\hline Incidence rate per day & 85.5 & 69.4 & 78.4 & $<0.001$ \\
\hline \multicolumn{5}{|l|}{ Age in years } \\
\hline Mean (SD) & $32.7(19.0)$ & $34.5(19.8)$ & $34.9(19.9)$ & $<0.001$ \\
\hline $1-18(\%)$ & 26.6 & 24.0 & 23.1 & 0.002 \\
\hline $19-64(\%)$ & 66.0 & 67.1 & 67.2 & 0.527 \\
\hline$\geq 65(\%)$ & 7.4 & 9.0 & 9.8 & 0.002 \\
\hline Female sex $(\%)$ & 49.1 & 46.1 & 48.5 & 0.042 \\
\hline \multicolumn{5}{|l|}{ Appendicitis (\%) } \\
\hline Complex acute & 21.2 & 27.0 & 23.6 & $<0.001$ \\
\hline Simple acute & 70.1 & 69.2 & 70.8 & 0.390 \\
\hline Non-acute & 8.6 & 3.8 & 5.7 & $<0.001$ \\
\hline Elixhauser score; mean (SD) & $0.7(2.9)$ & $0.7(3.1)$ & $0.8(3.2)$ & 0.985 \\
\hline LOS, days; mean (SD) & $4.3(3.6)$ & $4.3(3.6)$ & $4.3(3.2)$ & 0.567 \\
\hline CAA cases & 763 & 786 & 776 & \\
\hline Incidence rate per day & 18.2 & 18.7 & 18.5 & 0.8373 \\
\hline \multicolumn{5}{|l|}{ Age in years } \\
\hline Mean (sd) & $42.4(23.1)$ & $41.9(23.2)$ & $44.2(23.5)$ & 0.118 \\
\hline $1-18(\%)$ & 21.9 & 21.4 & 19.1 & 0.348 \\
\hline $19-64(\%)$ & 59.4 & 59.9 & 59.0 & 0.935 \\
\hline$\geq 65(\%)$ & 18.7 & 18.7 & 21.9 & 0.191 \\
\hline Female sex $(\%)$ & 41.0 & 41.2 & 43.3 & 0.603 \\
\hline Elixhauser score; mean (SD) & $1.9(4.4)$ & $1.8(4.4)$ & $1.8(4.4)$ & 0.431 \\
\hline LOS, days; mean (SD) & $6.9(5.2)$ & $6.8(5.0)$ & $6.9(4.7)$ & 0.844 \\
\hline SAA cases & 2518 & 2016 & 2330 & \\
\hline Incidence rate per day & 60.0 & 48.0 & 55.5 & $<0.001$ \\
\hline \multicolumn{5}{|l|}{ Age in years } \\
\hline Mean (sd) & $30.1(17.0)$ & $31.8(17.7)$ & $32.2(17.8)$ & $<0.001$ \\
\hline $1-18(\%)$ & 27.7 & 25.2 & 24.4 & 0.026 \\
\hline $19-64(\%)$ & 67.6 & 69.1 & 69.4 & 0.371 \\
\hline$\geq 65(\%)$ & 4.7 & 5.6 & 6.2 & 0.061 \\
\hline Female sex $(\%)$ & 49.0 & 46.9 & 49.0 & 0.273 \\
\hline Elixhauser score; mean (SD) & $0.4(2.3)$ & $0.4(2.3)$ & $0.5(2.6)$ & 0.868 \\
\hline LOS, days; mean (SD) & $3.6(2.5)$ & $3.4(2.1)$ & $3.5(1.8)$ & $<0.001$ \\
\hline NAA cases & 310 & 112 & 186 & \\
\hline Incidence rate per day & 7.4 & 2.7 & 4.4 & $<0.001$ \\
\hline \multicolumn{5}{|l|}{ Age in years } \\
\hline Mean (SD) & $29.1(15.4)$ & $31.5(15.1)$ & $30.2(15.9)$ & 0.186 \\
\hline $1-18(\%)$ & 29.0 & 19.6 & 22.6 & 0.086 \\
\hline $19-64(\%)$ & 69.0 & 79.5 & 73.7 & 0.095 \\
\hline$\geq 65(\%)$ & 1.9 & 0.9 & 3.8 & 0.230 \\
\hline Female sex $(\%)$ & 70.0 & 66.1 & 62.9 & 0.257 \\
\hline Elixhauser score; mean (SD) & $0.2(1.9)$ & $-0.1(2.1)$ & $0.5(3.4)$ & 0.038 \\
\hline LOS, days; mean (SD) & $3.7(2.4)$ & $4.1(4.4)$ & $4.1(3.6)$ & 0.577 \\
\hline
\end{tabular}

LOS length of stay

Furthermore, the patient age and gender were influenced by lockdown and easing. While the mean age significantly increased during lockdown and easing (32.7 vs. 34.5 and 34.9 years; $p<0.001$ ), the proportion of women decreased particularly during lockdown $(49.1 \%$ vs. $46.1 \%$ vs. $48.5 \%, p=$ 0.042). 
Comorbidities, evaluated using the Elixhauser score, were generally low, but highest in the CAA cases (1.8-1.9) and lowest in the NAA cases ( -0.1 to 0.5$)$. A significant difference between the periods was only observed for NAA cases ( 0.2 vs. -0.1 vs. $0.5, p=0.038)$. Further significant change in length of stay was only observed for SAA cases (3.6 vs. 3.4 vs. $3.5, p<0.001)$. It was shortened during the lockdown and increased again after the easing, but not to the old level.

\section{Comparison of appendectomy rates 2020 to 2019 and 2019 to 2018}

The examination of the three periods within 2020 already showed some effects of the lockdown and the easing on the study population. In the following, the three periods were examined within subgroups in relation to a common reference point, the previous year (2019).

Figure 1 shows the weekly numbers of cases for 2018, 2019, and 2020. Overall, as well as for SAA and NAA cases, the weekly case number decreases with start of the lockdown. In the easing period, the weekly case number increases again, but not to the pre-lockdown level. For CAA cases, no effects were visible.

Looking at all cases, a significant case reduction was observed for the lockdown (IR: $0.83, p<0.001$ ) and easing period (IR: $0.87, p<0.001$ ). However, only patients with
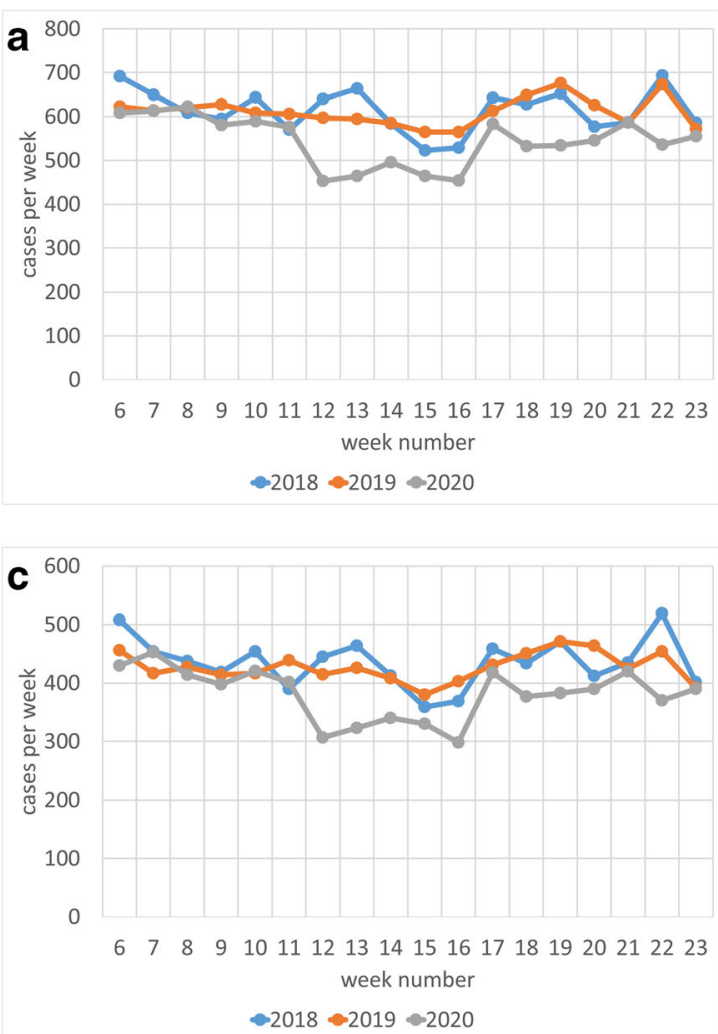

SAA (lockdown IR: 0.82, $p<0.001$; easing IR: 0.88, $p=$ 0.001 ) and especially NAA (lockdown IR: $0.32, p<0.001$; easing IR: $0.58, p<0.001$ ) were affected.

Regarding age groups, there was a significant case reduction in patients aged 1-18 and 19-64 in both the lockdown (118 IRR: $0.74, p<0.001 ; 19-64$ IRR: $0.85, p<0.001)$ and the easing period (1-18 IRR: $0.76, p<0.001$; 19-64 IRR: $0.89, p$ $=0.021$ ). Patients aged $1-18$ were most affected.

Considering gender, women in lockdown (IR: $0.79, p<$ 0.001 ) and easing (IR: $0.84, p<0.001$ ) period and men only in lockdown period (IR: $0.86, p=0.002$ ) showed a significant case reduction. The reduction was stronger for women.

When viewed together, gender- and age-specific effects were observed even if only SAA or NAA were considered. Particularly strong case reductions were observed in women aged $1-18$ with SAA in both lockdown (IR: $0.67, p<0.001$ ) and easing (IR: $0.73, p=0.011$ ) periods. The same applies to the NAA cases, only that the decrease in the number of cases is even stronger (lockdown IR: $0.23, p<0.001$; easing IR: $0.42, p<0.015$ ).

For CAA cases as well as patients aged $\geq 65$, no significant effects were observed.

To examine yearly case reductions without the influence of the pandemic, all comparisons shown in Table 2 were also done comparing 2019 to 2018 . No significant case reductions were observed.
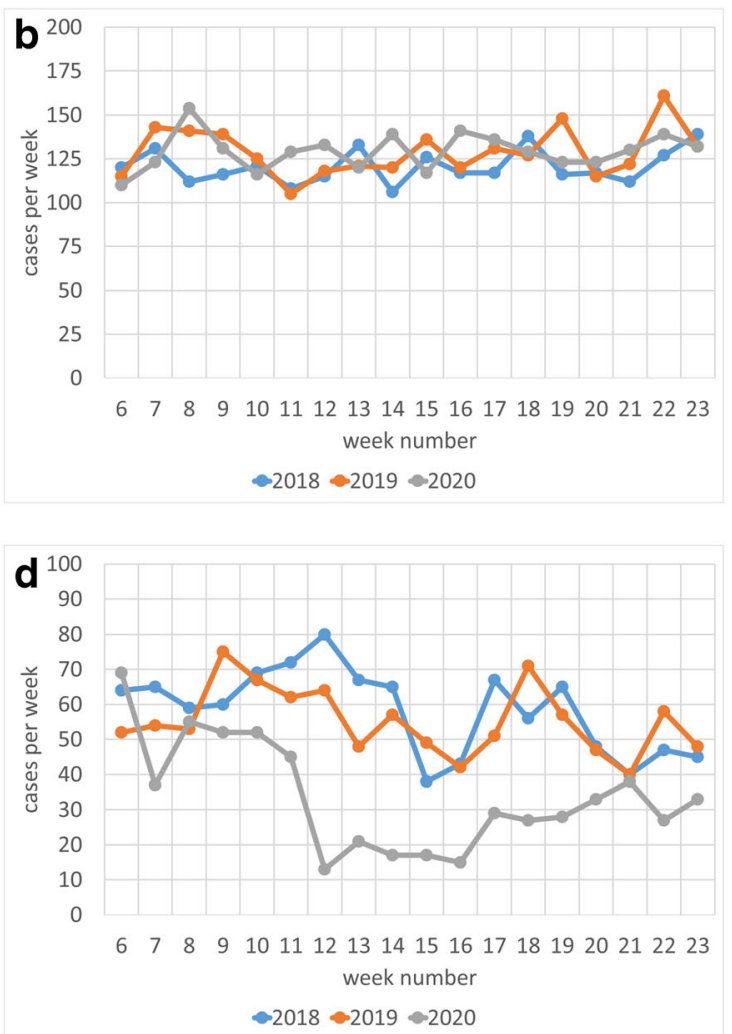

Fig. 1 Weekly case of patients with appendectomy. a ALL all appendicitis stages, b CAA complex acute appendicitis, $\mathbf{c}$ SAA simple acute appendicitis, and $\mathbf{d}$ NAA non-acute appendicitis 
Table 2 Incidence rate ratios (IRR) and adjusted $p$ values of hospital admissions with appendectomy in 2020 in reference to 2019 estimated by Poisson's regression. $A L L$, all appendicitis stages; $C A A$, complex acute appendicitis; $S A A$, simple acute appendicitis; $N A A$, non-acute appendicitis

\begin{tabular}{|c|c|c|c|c|c|c|c|c|c|c|c|c|}
\hline \multirow[t]{2}{*}{ Gender, age } & \multicolumn{3}{|l|}{ ALL } & \multicolumn{3}{|l|}{ CAA } & \multicolumn{3}{|l|}{ SAA } & \multicolumn{3}{|l|}{ NAA } \\
\hline & Before & Lockdown & Easing & Before & Lockdown & Easing & Before & Lockdown & Easing & Before & Lockdown & Easing \\
\hline All cases & $\begin{array}{l}0.97 \\
1.000\end{array}$ & $\begin{array}{l}0.83 \\
<0.001\end{array}$ & $\begin{array}{l}0.87 \\
<0.001\end{array}$ & $\begin{array}{l}0.99 \\
1.000\end{array}$ & $\begin{array}{l}1.05 \\
1.000\end{array}$ & $\begin{array}{l}0.96 \\
1.000\end{array}$ & $\begin{array}{l}0.98 \\
1.000\end{array}$ & $\begin{array}{l}0.82 \\
<0.001\end{array}$ & $\begin{array}{l}0.88 \\
0.001\end{array}$ & $\begin{array}{l}0.85 \\
1.000\end{array}$ & $\begin{array}{l}0.36 \\
<0.001\end{array}$ & $\begin{array}{l}0.58 \\
<0.001\end{array}$ \\
\hline $1-18$ & $\begin{array}{l}0.91 \\
1.000\end{array}$ & $\begin{array}{l}0.74 \\
<0.001\end{array}$ & $\begin{array}{l}0.76 \\
<0.001\end{array}$ & $\begin{array}{l}1.00 \\
1.000\end{array}$ & $\begin{array}{l}0.99 \\
1.000\end{array}$ & $\begin{array}{l}0.87 \\
1.000\end{array}$ & $\begin{array}{l}0.91 \\
1.000\end{array}$ & $\begin{array}{l}0.73 \\
<0.001\end{array}$ & $\begin{array}{l}0.77 \\
0.001\end{array}$ & $\begin{array}{l}0.80 \\
1.000\end{array}$ & $\begin{array}{l}0.28 \\
<0.001\end{array}$ & $\begin{array}{l}0.46 \\
0.004\end{array}$ \\
\hline $19-64$ & $\begin{array}{l}1.01 \\
1.000\end{array}$ & $\begin{array}{l}0.85 \\
<0.001\end{array}$ & $\begin{array}{l}0.89 \\
0.021\end{array}$ & $\begin{array}{l}1.04 \\
1.000\end{array}$ & $\begin{array}{l}1.09 \\
1.000\end{array}$ & $\begin{array}{l}0.98 \\
1.000\end{array}$ & $\begin{array}{l}1.01 \\
1.000\end{array}$ & $\begin{array}{l}0.85 \\
0.001\end{array}$ & $\begin{array}{l}0.90 \\
0.279\end{array}$ & $\begin{array}{l}0.90 \\
1.000\end{array}$ & $\begin{array}{l}0.41 \\
<0.001\end{array}$ & $\begin{array}{l}0.66 \\
0.022\end{array}$ \\
\hline$\geq 65$ & $\begin{array}{l}0.90 \\
1.000\end{array}$ & $\begin{array}{l}0.92 \\
1.000\end{array}$ & $\begin{array}{l}1.03 \\
1.000\end{array}$ & $\begin{array}{l}0.87 \\
1.000\end{array}$ & $\begin{array}{l}1.01 \\
1.000\end{array}$ & $\begin{array}{l}1.01 \\
1.000\end{array}$ & $\begin{array}{l}1.00 \\
1.000\end{array}$ & $\begin{array}{l}0.92 \\
1.000\end{array}$ & $\begin{array}{l}1.16 \\
1.000\end{array}$ & $\begin{array}{l}0.46 \\
1.000\end{array}$ & $\begin{array}{l}0.07 \\
1.000\end{array}$ & $\begin{array}{l}0.33 \\
1.000\end{array}$ \\
\hline Women & $\begin{array}{l}0.94 \\
1.000\end{array}$ & $\begin{array}{l}0.79 \\
<0.001\end{array}$ & $\begin{array}{l}0.84 \\
<0.001\end{array}$ & $\begin{array}{l}0.98 \\
1.000\end{array}$ & $\begin{array}{l}1.07 \\
1.000\end{array}$ & $\begin{array}{l}0.93 \\
1.000\end{array}$ & $\begin{array}{l}0.96 \\
1.000\end{array}$ & $\begin{array}{l}0.81 \\
<0.001\end{array}$ & $\begin{array}{l}0.87 \\
0.065\end{array}$ & $\begin{array}{l}0.81 \\
1.000\end{array}$ & $\begin{array}{l}0.33 \\
<0.001\end{array}$ & $\begin{array}{l}0.53 \\
<0.001\end{array}$ \\
\hline $1-18$ & $\begin{array}{l}0.90 \\
1.000\end{array}$ & $\begin{array}{l}0.64 \\
<0.001\end{array}$ & $\begin{array}{l}0.67 \\
<0.001\end{array}$ & $\begin{array}{l}0.97 \\
1.000\end{array}$ & $\begin{array}{l}0.90 \\
1.000\end{array}$ & $\begin{array}{l}0.58 \\
0.364\end{array}$ & $\begin{array}{l}0.88 \\
1.000\end{array}$ & $\begin{array}{l}0.67 \\
<0.001\end{array}$ & $\begin{array}{l}0.73 \\
0.011\end{array}$ & $\begin{array}{l}0.88 \\
1.000\end{array}$ & $\begin{array}{l}0.23 \\
<0.001\end{array}$ & $\begin{array}{l}0.42 \\
0.015\end{array}$ \\
\hline $19-64$ & $\begin{array}{l}0.96 \\
1.000\end{array}$ & $\begin{array}{l}0.85 \\
0.048\end{array}$ & $\begin{array}{l}0.89 \\
0.591\end{array}$ & $\begin{array}{l}1.04 \\
1.000\end{array}$ & $\begin{array}{l}1.25 \\
1.000\end{array}$ & $\begin{array}{l}1.02 \\
1.000\end{array}$ & $\begin{array}{l}0.98 \\
1.000\end{array}$ & $\begin{array}{l}0.86 \\
0.807\end{array}$ & $\begin{array}{l}0.90 \\
1.000\end{array}$ & $\begin{array}{l}0.79 \\
1.000\end{array}$ & $\begin{array}{l}0.38 \\
<0.001\end{array}$ & $\begin{array}{l}0.61 \\
0.035\end{array}$ \\
\hline$\geq 65$ & $\begin{array}{l}0.90 \\
1.000\end{array}$ & $\begin{array}{l}0.83 \\
1.000\end{array}$ & $\begin{array}{l}1.07 \\
1.000\end{array}$ & $\begin{array}{l}0.84 \\
1.000\end{array}$ & $\begin{array}{l}0.83 \\
1.000\end{array}$ & $\begin{array}{l}1.07 \\
1.000\end{array}$ & $\begin{array}{l}1.05 \\
1.000\end{array}$ & $\begin{array}{l}0.90 \\
1.000\end{array}$ & $\begin{array}{l}1.19 \\
1.000\end{array}$ & $\begin{array}{l}0.43 \\
1.000\end{array}$ & $\begin{array}{l}0.00 \\
1.000\end{array}$ & $\begin{array}{l}0.27 \\
1.000\end{array}$ \\
\hline Men & $\begin{array}{l}1.00 \\
1.000\end{array}$ & $\begin{array}{l}0.86 \\
0.002\end{array}$ & $\begin{array}{l}0.90 \\
0.227\end{array}$ & $\begin{array}{l}1.01 \\
1.000\end{array}$ & $\begin{array}{l}1.05 \\
1.000\end{array}$ & $\begin{array}{l}0.99 \\
1.000\end{array}$ & $\begin{array}{l}1.00 \\
1.000\end{array}$ & $\begin{array}{l}0.83 \\
0.001\end{array}$ & $\begin{array}{l}0.89 \\
0.341\end{array}$ & $\begin{array}{l}0.97 \\
1.000\end{array}$ & $\begin{array}{l}0.43 \\
0.002\end{array}$ & $\begin{array}{l}0.68 \\
1.000\end{array}$ \\
\hline $1-18$ & $\begin{array}{l}0.93 \\
1.000\end{array}$ & $\begin{array}{l}0.83 \\
0.759\end{array}$ & $\begin{array}{l}0.87 \\
1.000\end{array}$ & $\begin{array}{l}1.02 \\
1.000\end{array}$ & $\begin{array}{l}1.06 \\
1.000\end{array}$ & $\begin{array}{l}1.14 \\
1.000\end{array}$ & $\begin{array}{l}0.93 \\
1.000\end{array}$ & $\begin{array}{l}0.78 \\
0.279\end{array}$ & $\begin{array}{l}0.82 \\
1.000\end{array}$ & $\begin{array}{l}0.54 \\
1.000\end{array}$ & $\begin{array}{l}0.44 \\
1.000\end{array}$ & $\begin{array}{l}0.56 \\
1.000\end{array}$ \\
\hline $19-64$ & $\begin{array}{l}1.05 \\
1.000\end{array}$ & $\begin{array}{l}0.86 \\
0.039\end{array}$ & $\begin{array}{l}0.90 \\
1.000\end{array}$ & $\begin{array}{l}1.04 \\
1.000\end{array}$ & $\begin{array}{l}1.00 \\
1.000\end{array}$ & $\begin{array}{l}0.96 \\
1.000\end{array}$ & $\begin{array}{l}1.04 \\
1.000\end{array}$ & $\begin{array}{l}0.84 \\
0.067\end{array}$ & $\begin{array}{l}0.90 \\
1.000\end{array}$ & $\begin{array}{l}1.19 \\
1.000\end{array}$ & $\begin{array}{l}0.48 \\
0.139\end{array}$ & $\begin{array}{l}0.77 \\
1.000\end{array}$ \\
\hline$\geq 65$ & $\begin{array}{l}0.90 \\
1.000\end{array}$ & $\begin{array}{l}1.01 \\
1.000\end{array}$ & $\begin{array}{l}0.98 \\
1.000\end{array}$ & $\begin{array}{l}0.89 \\
1.000\end{array}$ & $\begin{array}{l}1.20 \\
1.000\end{array}$ & $\begin{array}{l}0.95 \\
1.000\end{array}$ & $\begin{array}{l}0.95 \\
1.000\end{array}$ & $\begin{array}{l}0.93 \\
1.000\end{array}$ & $\begin{array}{l}1.12 \\
1.000\end{array}$ & $\begin{array}{l}0.50 \\
1.000\end{array}$ & $\begin{array}{l}0.11 \\
1.000\end{array}$ & $\begin{array}{l}0.40 \\
1.000\end{array}$ \\
\hline
\end{tabular}

\section{Discussion}

COVID-19 confinement measures were associated with a clear decline in the number of patients presenting to the emergency services for i.e. heart problems, bowel obstruction, and appendicitis [6]. Only sparse data are available on the relation of COVID-19 confinement on the number of emergency surgical procedures. This study investigated the influence of COVID-19 confinement measures on the number and composition of patients that underwent appendectomy. The study revealed a significant decrease of appendectomies during the lockdown in 2020 compared to 2019 and 2018 in Germany.

Similar to our results, Tanel et al. reported data from Israel showing a decrease of acute appendicitis cases, which was not accompanied by an increase of complicated cases [7].

A single-center study from New York, focusing on pediatric patients, showed no differences in the number of appendicitis cases during the lockdown [8]. However, this study revealed a high number of patients treated non-operatively for appendicitis. Patients treated non-operatively were not investigated in our study.

Another single center study from Madrid reported a higher proportion of appendectomies due to complex acute appendicitis during the lockdown [9]. Our study showed similar results when rating the data relatively only for 2020 .

The numbers of appendectomies for complex acute appendicitis remained unchanged in our series, whereas the numbers for simple acute and non-acute appendicitis were significantly reduced. Interestingly, the number of non-acute appendicitis was reduced by more than $50 \%$. The proportion of acute complex appendicitis raised relatively in the investigated time period in 2020.

Looking and the subgroups revealed, that the younger the patient and the milder the appendicitis, the more the relative number of cases decreased. Further, women were more affected than men. Consequently, the largest reduction was observed for women until 18 years in the NAA group. The case reduction in this group was over $75 \%$. It has been shown previously that female patients are overrepresented in appendectomies in several age groups, i.e., until 18 years [10].

It could be speculated that during COVID-19 lockdown, patients with mild symptoms were not seeking medical care because of concern about acquiring COVID-19 infection. It might be that those cases resolved on their own. Here additional research is needed, as data from outpatient medical care 
was not available at the time of analysis. Another hypotheses might be that during the lockdown, more patients with mild symptoms were treated conservatively in an outpatient setting. According to Harnoss et al., this might lead to an increase of appendectomies during the following year, due to persistent, worsening, or recurrent symptoms [11].

Another possible explanation for the observed reduction of appendectomy cases is that the hospitals focused only on urgent cases in accordance with the lockdown recommendations. However, the reduced number of simple acute appendicitis did not lead to an increase of complex acute appendicitis, which could have been expected during the lockdown. Our study could not confirm results of previous reports, which showed an increase of complicated appendicitis. This might be due to the fact that these previous reports focused on very small, regional patient groups.

Our study further showed significant differences between the periods in terms of comorbidities for the NAA cases and length of stay for the SAA cases. Although these differences were statistically significant, it must be noted that they were very low and of no clinical relevance.

Considering our results, the lockdown demonstrated that reducing the number of appendectomies in simple acute and non-acute appendicitis does not lead to an increase in complicated acute appendicitis. Assuming that these cases did not require an appendectomy or were successfully treated conservatively, this approach could be continued after the end of the pandemic. This would reduce the number of appendectomies in cases with mild appendicitis, especially for women.

\section{Limitations}

The study has a number of limitations. It is based on secondary analysis of administrative claims data. Underor overdocumentation of individual diagnoses cannot be ruled out. Furthermore, there are limitations with regard to external validity of the patient characteristics and reported incidences since the patient collective studied was composed exclusively of AOK-insured persons. Although the collective of AOK-insured persons accounts for more than one-third of hospital cases in Germany, there are certain differences versus the population of persons insured by other statutory sickness funds in terms of the age structure and comorbidity profile [12]. For example in 2017, the appendectomy rate of the AOK population was $7 \%$ below the national average. The reported case reduction is also influenced by changes of the AOK collective between the years. The number of insured persons slightly rose from 2019 to 2020 , so that case reductions might be slightly underestimated. However, the differences between the years were less than $2 \%$ within each group.

\section{Conclusion}

The COVID-19 lockdown resulted in a reduced number of appendectomies but not in an increased number of acute complicated appendicitis. The study provides no evidence that the confinement measures resulted in a deterioration of medical care for appendicitis.

Authors' contributions MM performed study conception, acquisition of data, analysis and interpretation of data, and drafting of the manuscript. CG performed study conception, analysis and interpretation of data, drafting of the manuscript, and critical revision of the manuscript. HJM performed study conception and critical revision of the manuscript. CDH performed study conception and critical revision of the manuscript. UR performed study conception, drafting of the manuscript, and critical revision of the manuscript

Funding Open Access funding enabled and organized by Projekt DEAL.

Data availability The authors confirm that the data utilized in this study cannot be made available in the manuscript, the supplemental files, or in a public repository due to German data protection laws ("Bundesdatenschutzgesetz," BDSG). Therefore, they are stored on a secure drive in the AOK Research Institute (WIdO), to facilitate replication of the results. Generally, access to data of statutory health insurance funds for research purposes is possible only under the conditions defined in German Social Law (SGB V § 287). Requests for data access can be sent as a formal proposal specifying the recipient and purpose of the data transfer to the appropriate data protection agency. Access to the data used in this study can only be provided to external parties under the conditions of the cooperation contract of this research project and after written approval by the sickness fund. For assistance in obtaining access to the data, please contact christian.guenster@wido.bv.aok.de.

\section{Compliance with ethical standards}

Conflict of interest The authors declare that there are no conflicts of interest.

Ethical statement This article does not contain any studies with human participants performed by any of the authors.

Open Access This article is licensed under a Creative Commons Attribution 4.0 International License, which permits use, sharing, adaptation, distribution and reproduction in any medium or format, as long as you give appropriate credit to the original author(s) and the source, provide a link to the Creative Commons licence, and indicate if changes were made. The images or other third party material in this article are included in the article's Creative Commons licence, unless indicated otherwise in a credit line to the material. If material is not included in the article's Creative Commons licence and your intended use is not permitted by statutory regulation or exceeds the permitted use, you will need to obtain permission directly from the copyright holder. To view a copy of this licence, visit http://creativecommons.org/licenses/by/4.0/.

\section{References}

1. De Filippo O, D'Ascenzo F, Angelini F et al (2020) Reduced rate of hospital admissions for ACS during Covid-19 outbreak in Northern Italy. N Engl J Med 383:88-89. https://doi.org/10.1056/ NEJMc2009166 
2. Dreifuss NH, Schlottmann F, Sadava EE, Rotholtz NA (2020) Acute appendicitis does not quarantine: surgical outcomes of laparoscopic appendectomy in COVID-19 times. Br J Surg. https://doi. org/10.1002/bjs.11806

3. Snapiri O, Rosenberg Danziger C, Krause I, Kravarusic D, Yulevich A, Balla U, Bilavsky E (2020) Delayed diagnosis of paediatric appendicitis during the COVID-19 pandemic. Acta Paediatr 109:1672-1676. https://doi.org/10.1111/apa.15376

4. Kölfel W (2020) RP online, https://rp-online.de/nrw/panorama/ kinderaerzte-warnen-eltern-zoegern-arztbesuche-wegen-coronahinaus_aid-50230583. Accessed 25 April 2020

5. van Walraven C, Austin PC, Jennings A, Quan H, Forster AJ (2009) A modification of the Elixhauser comorbidity measures into a point system for hospital death using administrative data. Med Care 47(6):626-633. https://doi.org/10.1097/mlr. $0 \mathrm{~b} 013 \mathrm{e} 31819432 \mathrm{e} 5$

6. Masroor S (2020) Collateral damage of COVID-19 pandemic: delayed medical care. J Card Surg 35:1345-1347. https://doi.org/10. 1111/jocs. 14638

7. Tankel J, Keinan A, Blich O, Koussa M, Helou B, Shay S, Zugayar D, Pikarsky A, Mazeh H, Spira R, Reissman P (2020) The decreasing incidence of acute appendicitis during COVID-19: a retrospective multi-centre study. World J Surg 44:2458-2463. https://doi. org/10.1007/s00268-020-05599-8

8. Kvasnovsky CL, Shi Y, Rich BS et al (2020) Limiting hospital resources for acute appendicitis in children: lessons learned from the U.S. epicenter of the COVID-19 pandemic. J Pediatr Surg:6-10. https://doi.org/10.1016/j.jpedsurg.2020.06.024

9. Velayos M, Muñoz-Serrano AJ, Estefanía-Fernández K, Sarmiento Caldas MC, Moratilla Lapeña L, López-Santamaría M, LópezGutiérrez JC (2020) Influencia de la pandemia por coronavirus 2 (SARS-Cov-2) en la apendicitis aguda. An Pediatr (Barc) 93:118122. https://doi.org/10.1016/j.anpedi.2020.04.022

10. Rolle U, Maneck M (2016) Versorgungstrends, regionale Variation und Qualität der Versorgung bei Appendektomien. In: Klauber J, Günster C, Schmacke N et al (eds) Versorgungsreport 2015/2016. Schattauer, Stuttgart, pp 217-238

11. Harnoss JC, Zelienka I, Probst P, Grummich K, Müller-Lantzsch C, Harnoss JM (2017) Antibiotics versus surgical therapy for uncomplicated appendicitis: systematic review and meta-analysis of controlled trials. Ann Surg 265(5):889-900

12. Hoffmann F, Icks A (2012) Unterschiede in der Versichertenstruktur von Krankenkassen und deren Auswirkungen für die Versorgungsforschung: Ergebnisse des Bertelsmann-Gesundheitsmonitors. Gesundheitswesen 74:291297. https://doi.org/10.1055/s-0031-1275711

Publisher's note Springer Nature remains neutral with regard to jurisdictional claims in published maps and institutional affiliations. 